\title{
A STUDY OF ANTIMICROBIAL SUSCEPTIBILITY PATTERN OF CLINICAL ISOLATES OF ACINETO- BACTER SPECIES AT A TERTIARY CARE HOSPITAL IN CENTRAL INDIA
}

\author{
Minal Vasant Kusalkar1 ${ }^{1}$ Agrawal Seema M², Katkar Vyankatesh $J^{3}$ \\ 1 Postgraduate Student, Department of Microbiology, Government Medical College and Hospital, Nagpur. \\ ${ }^{2}$ Associate Professor, Department of Microbiology, Government Medical College and Hospital, Nagpur. \\ 3 Professor and HOD, Department of Microbiology, Government Medical College and Hospital, Nagpur.
}

\section{BACKGROUND}

ABSTRACT

Acinetobacter have been implicated in a variety of nosocomial infections including ventilator associated pneumonia, bacter aemia, urinary tract infection, secondary meningitis and in patients confined to hospital intensive care units. Multidrug resistant Acinetobacter species have limited the options for effective treatment.

The present study was undertaken to isolate and identify the multidrug resistant (MDR) and pan drug resistant (PDR) Acinetobacter species and also to determine minimum inhibitory concentration of tigecycline using agar dilution method.

\section{MATERIALS AND METHODS}

This is a prospective study conducted over a period of 22 months (January 2014 to October 2015) in a tertiary care hospital. Ninety-six non-duplicate clinical isolates of Acinetobacter species were processed for species identification by standard Microbiological procedures. Antimicrobial susceptibility of these isolates was performed by Kirby-Bauer disc diffusion method and minimum inhibitory concentration of Tigecycline was tested using agar dilution method.

\section{RESULTS}

A. baumannii was the most common species isolated accounting for $82.29 \%$ followed by A. calcoaceticus (10.41\%), A. haemolyticus (3.12\%), A. Iwoffii (3.12\%) and A. junii (1.04\%). Isolates from ICU specimens is significantly higher than ward (p value $<0.05) .89$ $(92.71 \%)$ out of 96 Acinetobacter isolates were multidrug resistant and there was no isolate which was found to be PDR. By MIC agar dilution methods for tigecycline, $82(85.41 \%)$ isolates were found to be sensitive to tigecycline.

\section{CONCLUSION}

Increasing use of antibiotics in hospitals is leading towards antibiotic resistance, which in turn exerts selective pressure on Acinetobacter in hospital environment. Continued surveillance combined with preventive measures remains absolutely essential in efforts to prevent or limit spread of Acinetobacter and resulting infections.

\section{KEYWORDS}

Acinetobacter, Multidrug Resistant, Pan Drug Resistant, Tigecycline, Minimum Inhibitory Concentration.

HOW TO CITE THIS ARTICLE: Kusalkar MV, Seema AM, Vyankatesh KJ. A study of antimicrobial susceptibility pattern of clinical isolates of Acinetobacter species at a tertiary care hospital in central India. J. Evolution Med. Dent. Sci. 2018;7(01):53-57, DOI: 10.14260/jemds/2018/14

\section{BACKGROUND}

Among myriad living organisms, Acinetobacter species have quickly gone from being an unknown and unnamed organism to becoming amongst the most dangerous pathogenic organism of present times.(1) Over the last 30 years, gram negative bacilli have proved to be a particular problem in causing human infection. After the therapeutic introduction of newer broad-spectrum antibiotics in hospitals, an increase in the incidence of resistance is seen in Acinetobacter species.(2) They have been implicated in a variety of nosocomial infections including bacteraemia, urinary tract infection and secondary meningitis, but their role as agents of nosocomial pneumonia, particularly ventilator associated pneumonia in patients confined to hospital intensive care

'Financial or Other Competing Interest': None.

Submission 05-11-2017, Peer Review 17-12-2017,

Acceptance 22-12-2017, Published 01-01-2018.

Corresponding Author:

Dr. Minal Vasant Kusalkar,

Room No. 36,

Waman Wadi, V. N. Purav Marg,

Chembur, Mumbai-40071

E-mail: minal.k37@gmail.com

DOI: $10.14260 /$ jemds $/ 2018 / 14$

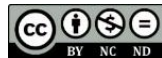

units is important.(3) In addition to infection among hospitalised patients, community-acquired Acinetobacter infections is increasingly reported. The common and important representative of the genus is Acinetobacter baumannii and other species such as Acinetobacter lwoffii, Acinetobacter johnsonii and Acinetobacter haemolyticus are less frequently isolated from patients.(4)

Predisposing factors for Acinetobacter infections include presence of prosthesis, endotracheal intubation, intravenous catheters and prior antibiotic therapy in a seriously ill patient in hospital.(5) Such infections are often extremely difficult for the clinician to treat, because of increasing resistance of these bacteria to the major groups of antibiotics. Of particular concern, A. baumannii strains exhibiting resistance to carbapenems which were previously considered the treatment of choice for infected patients have dramatically increased worldwide, leaving a few antibacterial choices. Tigecycline, a broad-spectrum modified minocycline derivative, is considered as a last resort drug against multidrug-resistant $A$. baumannii. Though, resistance to tigecycline has emerged and is growing notably following increasing tigecycline usage.(6) For this study, Multidrug resistant (MDR) Acinetobacter spp. are defined as those isolates resistant to more than three classes of antibiotics. 
Pan drug resistant (PDR) Acinetobacter spp. are those resistant to all the commonly used antibiotics.(7)

\section{MATERIALS AND METHODS \\ Study Design \\ Descriptive type of study.}

\section{Sample Collection}

The present prospective study was conducted in the Department of Microbiology at a tertiary level teaching health care facility over a period of 22 months (January 2014 to October 2015). Ninety six non-duplicate Acinetobacter isolates recovered from the urine, pus, blood, respiratory samples such as endotracheal aspirates, bronchoalveolar lavage (BAL), CSF and other body fluids were included in the study.

\section{Isolation and Identification of Acinetobacter Species}

For the isolation of Acinetobacter spp., the clinical samples were inoculated onto blood agar and MacConkey agar. After overnight incubation at $37^{\circ} \mathrm{C}$, the suspected colonies were further processed by standard microbiological methods. ${ }^{(8)}$ Speciation of the Acinetobacter isolates was done as per the biochemical tests described in Table 1.(9)

\section{Antimicrobial Susceptibility Testing}

The antimicrobial susceptibility testing of all the 96 Acinetobacter isolates was carried out by Kirby-Bauer disc diffusion method on Mueller-Hinton agar medium and results were interpreted as per the Clinical and Laboratory Standards Institute guidelines. ${ }^{(10)}$

Antimicrobial discs used in the study were procured from Hi-Media Laboratories, Mumbai, India. Following antibiotic discs were put up with the concentration of the compound mentioned in the parenthesis: ceftazidime $(30 \mu \mathrm{g})$, imipenem $(10 \mu \mathrm{g})$, meropenem $(10 \mu \mathrm{g})$, gentamicin $(10 \mu \mathrm{g})$, tobramycin $(10 \mu \mathrm{g})$, ampicillin-sulbactam $(10 / 10 \mu \mathrm{g})$, ciprofloxacin $(5$ $\mu \mathrm{g})$, piperacillin $(100 \mu \mathrm{g})$, piperacillin-tazobactam $(100 / 10$ $\mu \mathrm{g})$, ticarcillin-clavulanic acid $(75 / 10 \mu \mathrm{g})$, cefepime $(30 \mu \mathrm{g})$, cefotaxime $(30 \mu \mathrm{g})$, ceftriaxone $(30 \mu \mathrm{g})$, amikacin $(30 \mu \mathrm{g})$, tetracycline $(30 \mu \mathrm{g}), \quad$ trimethoprim-sulfamethoxazole $(1.25 / 23.75 \mu \mathrm{g})$, Polymyxin B and tigecycline $(15 \mu \mathrm{g})$.

\section{Testing of Metallo- $\beta$-Lactamase (MBL) Production}

Imipenem resistant isolates were further screened for metallo-beta-lactamase production by combination disc test.(11)

\section{Minimum Inhibitory Concentration (MIC)}

MIC for all Acinetobacter isolates was determined for tigecycline (TG) by agar dilution method,(12) tigecycline powder procured from Hi-Media Laboratories.

\section{Statistical Analysis}

Percentage were used to describe the proportion. Chi-square test was used as the test of significance for categorical variables. ' $P$ ' value less than 0.05 was considered to be statistically significant.

\section{RESULTS}

A total of 96 non-duplicate, non-consecutive Acinetobacter isolates were processed for species identification, antimicrobial susceptibility testing and to know the MDR and PDR pattern of these isolates. A total of 5681 clinical samples were processed, of which 96 (1.69\%) strains of Acinetobacter were isolated. Table 2 shows that 71 (1.29\%) Acinetobacter strains were isolated from 5480 specimens of ward and 25(12.44\%) isolates were from 201 ICU specimens. Percentage of Isolates from ICU specimens is higher than ward. A. baumannii was the most common species isolated accounting for $82.29 \%$ followed by $A$. calcoaceticus $(10.41 \%)$, A. haemolyticus (3.12\%), A. Iwoffii $(3.12 \%)$ and A. junii (1.04\%). The percentage of isolation of $A$. baumannii was higher $(82.29 \%)$ as compared to other species $(17.71 \%)$. The pattern of distribution of Acinetobacter species in various infections is reflected in Table 3. The antimicrobial susceptibility pattern of Acinetobacter is shown in Table 4 Table 4 shows $100 \%$ sensitivity to Polymyxin B, $85.42 \%$ to Tigecycline, $75 \%$ to ampicillin-sulbactam, $66.66 \%$ sensitive to Imipenem and $62.50 \%$ to meropenem. Maximum resistance was seen to ciprofloxacin (97.91\%) followed by piperacillin $95.83 \%$, cefepime $(90.60 \%)$, cotrimoxazole $(85.42 \%)$ and cefotaxime $(81.25 \%)$. Imipenem resistance was seen in 32 $(33.33 \%)$ isolates. $89(92.71 \%)$ out of 96 Acinetobacter isolates were multidrug resistant and 7 (7.29\%) were nonMDR. None of the isolates recovered was resistant to Polymyxin B. Thus, there was no isolate, which was found to be PDR. Acinetobacter isolates recovered from ICU patients were found to be more drug resistant than those isolated from ward and outdoor patients. 32 imipenem resistant isolates were tested for MBL production. Out of the total 32 imipenem resistant Acinetobacter isolates, 28 (87.5\%) were MBL producer and all of them were A. baumannii strains. By MIC agar dilution and disc diffusion methods for tigecycline, $82(85.41 \%)$ isolates were found to be sensitive to tigecycline. Disc diffusion showed 14 isolates as resistant, of which 9 turned out to be intermediate and only 5 as resistant by MIC.

\begin{tabular}{|c|c|c|c|c|c|c|}
\hline \multirow{2}{*}{ 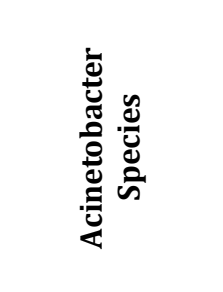 } & \multicolumn{2}{|c|}{$\sum_{0}^{\pi}$} & \multirow{2}{*}{$\frac{\sqrt[n]{n}}{\frac{2}{0}}$} & \multirow{2}{*}{ 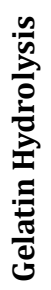 } & \multirow{2}{*}{ 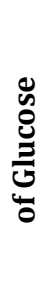 } & \multirow{2}{*}{ 总 } \\
\hline & $\begin{array}{l}0 \\
\text { 잇 } \\
\text { n}\end{array}$ & $\begin{array}{l}\text { ن } \\
\text { 인 } \\
\dot{+}\end{array}$ & & & & \\
\hline A. baumannii & + & + & - & - & + & + \\
\hline A. calcoaceticus & + & - & - & - & + & + \\
\hline A. haemolyticus & + & - & + & + & $\mathrm{V}$ & + \\
\hline A. lwoffii & + & - & - & - & - & - \\
\hline A. junii & + & - & - & - & - & + \\
\hline A. johnsonii & - & - & - & - & - & $\mathbf{V}$ \\
\hline
\end{tabular}

\begin{tabular}{|c|c|c|c|}
\hline \multirow{2}{*}{ Wards } & No. of Specimens & \multicolumn{2}{|c|}{ Acinetobacter Isolates } \\
\cline { 3 - 4 } & Processed & Number & Percentage \\
\hline Wards & 5480 & 71 & 1.29 \\
\hline ICU & 201 & 25 & 12.44 \\
\hline Total & $\mathbf{5 6 8 1}$ & $\mathbf{9 6}$ & $\mathbf{1 . 6 9}$ \\
\hline \multicolumn{2}{|r|}{ Table 2. Number of Acinetobacter Isolates } \\
\hline
\end{tabular}

( $\mathrm{p}$ value $<0.05)$ 


\begin{tabular}{|c|c|c|c|c|c|c|}
\hline Infection & $\begin{array}{c}\text { A. baumannii } \\
(\%)\end{array}$ & $\begin{array}{c}\text { A. calcoaceticus } \\
(\%)\end{array}$ & \begin{tabular}{|c|}
$\begin{array}{c}\text { A. haemolyticus } \\
(\%)\end{array}$ \\
\end{tabular} & $\begin{array}{l}\text { A. lwoffii } \\
(\%)\end{array}$ & $\begin{array}{c}\text { A. junii } \\
(\%)\end{array}$ & $\begin{array}{c}\text { Total } \\
\text { (n) }\end{array}$ \\
\hline $\begin{array}{l}\text { Skin and soft tissue } \\
\text { infection }\end{array}$ & $38(86.36)$ & $5(11.36)$ & $1(2.28)$ & & - & 44 \\
\hline Septicaemia & $14(63.64)$ & $2(9.09)$ & $2(9.09)$ & $3(13.63)$ & $1(4.54)$ & 22 \\
\hline Pneumonia & $13(86.67)$ & $2(13.33)$ & & & & 15 \\
\hline UTI & $6(85.72)$ & $1(14.28)$ & & & & 7 \\
\hline Ascites & 5 & - & & & & 5 \\
\hline Pleural effusion & 2 & - & & & & 2 \\
\hline Meningitis & 1 & - & & & & 1 \\
\hline Total & 79 & 10 & 3 & 3 & 1 & 96 \\
\hline
\end{tabular}

\begin{tabular}{|c|c|c|c|}
\hline \multirow[t]{2}{*}{ Group } & \multirow[t]{2}{*}{ Antimicrobial Agent } & \multicolumn{2}{|c|}{$\begin{array}{c}\text { Resistant Isolates } \\
(\mathrm{n}=96)\end{array}$} \\
\hline & & No. & $\%$ \\
\hline \multirow[t]{7}{*}{ Group A } & Ceftazidime (CAZ) & 72 & 75.00 \\
\hline & Imipenem (IMP) & 32 & 33.33 \\
\hline & Meropenem (MRP) & 36 & 37.50 \\
\hline & Gentamycin (G) & 76 & 79.16 \\
\hline & Tobramycin (TOB) & 78 & 81.25 \\
\hline & Ampicillin sulbactam (AS) & 24 & 25.00 \\
\hline & Ciprofloxacin (CIP) & 94 & 97.91 \\
\hline \multirow[t]{9}{*}{ Group B } & Piperacillin (PIP) & 92 & 95.83 \\
\hline & Piperacillin-Tazobactam (PIT) & 72 & 75.00 \\
\hline & $\begin{array}{c}\text { Ticarcillin-Clavulanic acid } \\
\text { (TCC) }\end{array}$ & 78 & 81.25 \\
\hline & Cefepime (CPM) & 87 & 90.62 \\
\hline & Cefotaxime (CTX) & 78 & 81.25 \\
\hline & Ceftriaxone ( CTR) & 76 & 79.16 \\
\hline & Amikacin $(\mathrm{AK})$ & 72 & 75.00 \\
\hline & Tetracycline $(\mathrm{T})$ & 80 & 83.33 \\
\hline & $\begin{array}{c}\text { Trimethoprim- } \\
\text { Sulfamethoxazole (COT) }\end{array}$ & 82 & 85.42 \\
\hline Group 0 & Polymyxin (PB) & 0 & - \\
\hline Other & Tigecycline (TGC) & 14 & 14.58 \\
\hline & $\begin{array}{r}\text { 4. Antimicrobial Sensit } \\
\text { Acinetobacter Isolates }\end{array}$ & 96) & \\
\hline
\end{tabular}

\begin{tabular}{|c|c|c|c|}
\hline \multirow[t]{2}{*}{ Wards } & \multirow{2}{*}{$\begin{array}{c}\text { Total No. } \\
\text { of Isolates }\end{array}$} & \multicolumn{2}{|c|}{ MDR Isolates } \\
\hline & & Number & Percentage \\
\hline ICU & 25 & 25 & 100.00 \\
\hline Surgery & 34 & 31 & 91.18 \\
\hline $\begin{array}{l}\text { Obstetrics and } \\
\text { Gynaecology }\end{array}$ & 11 & 10 & 90.90 \\
\hline Medicine & 15 & 14 & 93.33 \\
\hline Paediatrics & 8 & 7 & 87.50 \\
\hline Orthopaedics & 3 & 2 & 66.66 \\
\hline Total & 96 & 89 & 92.70 \\
\hline $\begin{array}{r}\text { Table 5. Distrib } \\
\text { Isola }\end{array}$ & $\begin{array}{l}\text { on of Multi } \\
\text { in various }\end{array}$ & spital $W$ & $\begin{array}{l}\text { stant (MDR) } \\
\text { ds }\end{array}$ \\
\hline
\end{tabular}

\section{DISCUSSION}

Acinetobacter species are contributing profoundly to the burden of modern medicine, where the term 'burden' refers to the sum of clinical and economic load.(13) The rate of isolation of Acinetobacter species from our study was $1.6 \%$. Various other studies have reported the rate of isolation varying from $1.54 \%$ to $20.1 \%$ (Jaggi et al(14) 2012), Dash et al (2013) and Behera et al 2011.(15) This variation can be attributed to the varying prevalence rates of different Acinetobacter species in the hospital environment and the community in different geographical areas. However, $A$. baumannii is seldom recognised as a true environmental

organism. As other study groups (Idomir et al,(16) Mindoli et al,(17) Tripathi et al,(18) A. baumannii was the most common species isolated accounting for $82.29 \%$ followed by $A$. calcoaceticus (10.41\%), A. haemolyticus (3.12\%), A. lwoffii (3.12\%) and $A$. junii (1.04\%). In this study, isolation of $A$. baumannii was significantly higher $(82.29 \%)$ as compared to other species $(17.71 \%)$. This was statistically significant with 'p' value less than 0.001 . Most common infection caused by Acinetobacter was skin and soft tissue infection (45.83\%) followed by septicaemia $(22.91 \%)$ and pneumonia (15.63\%). In the current study, among the different risk factors diabetes mellitus was the most common risk factor (41.67\%) associated with all types of Acinetobacter infections studied. This is concurrent with other studies (Tripathi et al). ${ }^{18}$ Along with prolonged hospital stay intravenous catheter $(63.64 \%)$ was the commonest risk factor in septicaemia, mechanical ventilation $(53.33 \%)$ was the commonest risk factor in pneumonia and urinary catheter $(85.71 \%)$ was the commonest risk factor in UTI. This is concurrent with other studies. In present study, Acinetobacter strains showed maximum sensitivity to polymyxin B (100\%) followed by tigecycline (85.42\%), ampicillin-sulbactam (75\%), imipenem (66.66\%) and meropenem (62.50\%). Maximum resistance was noted to ciprofloxacin (97.91\%). Resistance to piperacillin, cotrimoxazole and tetracycline was $95.83 \%$, $85.42 \%$ and 83.33 respectively. Among cephalosporins, out of 96 isolates $90.62 \%$ showed resistance to cefepime, $81.25 \%$ to cefotaxime, $79.16 \%$ to ceftriaxone and $75 \%$ to ceftazidime in our study. Taneja et al(19) in 2012 showed that the resistance of Acinetobacter to gentamicin, amikacin and ciprofloxacin was $79.5 \%, 73.2 \%$ and $72.8 \%$ respectively. Shareek et al in 2012 reported that only $25 \%$ of the strains were sensitive to carbapenems, $10 \%-15 \%$ of the strains were sensitive to $\beta$ lactams and $20 \%-28 \%$ of the strains were sensitive to amikacin, ciprofloxacin and cotrimoxazole.(20) Other studies have also shown similar results for different antimicrobial agents. ${ }^{(21,22)}$ Resistance to polymyxins has also been reported by many authors, $(20,23)$ but in our study we did not notice any resistance to these antibiotics. In the current study, out of 96 isolates 89 (92.71\%) were multidrug resistant (MDR). All the 25 isolates from ICU were MDR. Dash et al (2013) recorded MDR in $54.7 \%$ isolates. Badave et al(24) found $90.3 \%$ isolates to be MDR. Taneja et al(19) also reported $41.5 \%$ of the Acinetobacter isolates as MDR.(20) In our study of the 32 imipenem resistant Acinetobacter strains, 28 Acinetobacter were MBL producers, all of which were $A$. baumannii.

Goel et al(25) found $48.72 \%$ MBL producing strains in 2013, Kaur et al(26) in 2014 found MBL activity in $80.3 \%$ of isolates and Gupta et al(27) found 14.4\% MBL producing strains in 2015. By agar dilution method (Table 6) 82 
(85.41\%) isolates were found to be sensitive, 9 (9.38\%) isolates were found to be intermediate resistant and $5(5.21 \%)$ isolates were resistant. No isolate grew at MIC 16 microgram $/ \mathrm{mL}$. A study(28) in Singapore in 2007 Acinetobacter showed 9\% resistance, 20\% intermediate resistant and $71 \%$ sensitive to tigecycline by agar dilution method. In 2010, Manoharan et al(29) performed tigecycline MIC by agar dilution and E strip and found that more than $90 \%$ isolates of Acinetobacter were having $\mathrm{MIC}<8 \mathrm{mcg} / \mathrm{mL}$.

\section{CONCLUSION}

Acinetobacter baumannii has already been notified a "red alert" pathogen by the Infectious Disease Society of America. Acinetobacter is a leading cause of wide spectrum of infections, especially in critically ill patients in ICU patients. The high prevalence of multidrug resistant mechanism makes them the "superbug" of the hospital environment. Thus, there is urgent need to control the spread of this pathogen in various hospital areas. MIC detects intermediate resistant isolates, for which treatment is possible by increasing the concentration/ dose of drug. Thus, in case of MDR strains where treatment options are limited, carbapenems and tigecycline sensitivity testing should be done by MIC whenever possible. MBL production has been shown by Acinetobacter strains, thus laboratories are advised to set up MBL detection testing to identify and prevent the spread of MBL strains. Continued surveillance of prevalent organisms in ICUs and other wards of hospital combined with preventive measures (e.g. isolation precautions, hand disinfection, efficient sterilisation of instruments) remains absolutely essential in efforts to prevent or limit spread of Acinetobacter and resulting infection.

\section{REFERENCES}

[1] Bergogne-Berezin E. Introduction and perspectives. In: Bergogne-Berezin E, Friedman H, Bendinelli M. eds. Infectious agents and pathogenesis Acinetobacter biology and pathogenesis. New York: Springer Science, LLC 2008:13-6.

[2] Bergogne-Berezin E, Towner KJ. Acinetobacter spp. as nosocomial pathogens: microbiological, clinical and epidemiological features. Clin Microbiol Rev 1996;9(2):148-65.

[3] Villegas MV, Hartstein AI. Acinetobacter outbreaks, 1977-2000. Infect Control Hosp Epidemiol 2003;24(4):284-95.

[4] Peleg AY, Seifert H, Paterson DL. Acinetobacter baumannii: emergence of a successful pathogen. Clin Microbiol Rev 2008;21(3):538-82.

[5] Fallon RJ, Young H. Nesseria, Moraxella and Ainetobacter. In: Collee JG, Fraser AG, Marmion BP, et al. eds. Mackie and McCartney practical medical microbiology. 14th edn. New York: ChurchillLivingstone 1999:238-97.

[6] Pournaras S, Koumaki V, Gennimata V, et al. In vitro activity of tigecycline against acinetobacter baumannii: global epidemiology and resistance mechanisms. Adv Exp Med Biol 2016;897:1-14.

[7] Dash M, Padhi S, Misra P, et al. Frequency, risk factors and antibiogram of Acinetobacter species isolated from various clinical samples in a tertiary care hospital in Odisha, India. Avicenna J Med 2013;3(4):97-102.
[8] Collee JG, Marr W. Specimen collection, culture containers and media. In: Collee JG, Fraser AG, Marimon BP, et al. eds. Mackie \& McCartney practical medical microbiology. $14^{\text {th }}$ edn. New York: ChurchillLivingstone Publications 1999:95-112.

[9] Koneman EW, Allen SD, Jande WM, et al. The non fermentative Gram-negative bacilli. In: Koneman's colour atlas and textbook of diagnostic microbiology. $6^{\text {th }}$ edn. Philadelphia: Lippincott Williams and Wilkins 2006:303-91.

[10] CLSI 2015: Performance standard for antimicrobial susceptibility testing, eighteenth informational supplement, M100-S25. Clinical and laboratory standard institute. Wayne, PA, USA. 2015.

[11] Yong D, Lee K, Yum JH, et al. Imipenem-EDTA disk method for differentiation of metallo- $\beta$-lactamaseproducing clinical isolates of Pseudomonas spp. and Acinetobacter spp. J Clin Microbiol 2002;40(10):3798801.

[12] Miles RS, Amyes SG. Laboratory control of antimicrobial therapy. In: Collee JG, Fraser AG, Marmion BP, et al. eds. Mackie and McCartney practical medical microbiology.14th edn. New York: Churchill- Livingstone 1999:151-78.

[13] Towner KJ. Clinical importance and antibiotic resistance of Acinetobacter spp. Proceedings of a symposium held on 4-5 November 1996 at Eilat, Israel. J Med Microbiol 1997;46(9) 721-46.

[14] Jaggi N, Sissodia P, Sharma L. Acinetobacter baumannii isolates in a tertiary care hospital: antimicrobial resistance and clinical significance. Journal of Microbiology and Infectious Diseases 2012;2(2):5763.

[15] Behera B, Mathur P. High levels of antimicrobial resistance at a tertiary trauma care centre of India. Indian J Med Res 2011;133:343-5.

[16] Idomir M, Nemet C, Pascu A, et al. Acinetobacter spp. pathogenic role and resistance to antibiotics. Bulletin of the Transilvania University of Braşov 2009;2(51):44-58.

[17] Mindolli PB, Salmani MP, Vishwanath G, et al. Identification and speciation of acinetobacter and their antimicrobial susceptibility testing. Al Ameen J Med Sci 2010;3(4):345-9.

[18] Tripathi PC, Gajbhiye SR, Agrawal GN. Clinical and antimicrobial profile of Acinetobacter spp.: an emerging nosocomial superbug. Adv Biomed Res 2014;3:13.

[19] Taneja N, Singh G, Singh M, et al. Emergence of tigecycline and colistin resistant Acinetobacter baumannii in patients with complicated urinary tract infections in north India. Indian J Med Res 2011;133:681-4.

[20] Shareek PS, Sureshkumar D, Ramgopalakrishnan, et al. Antibiotic sensitivity pattern of blood isolates of Acinetobacter species in a tertiary care hospital: a retrospective analysis. Am J Infect Dis 2012;8(1):65-9.

[21] Goel N, Chaudhary U, Aggarwal R, et al. Antibiotic sensitivity pattern of gram negative bacilli isolated from the lower respiratory tract of ventilated patients in the intensive care unit. Indian J Crit Care Med 2009;13(3):148-51. 
[22] Karthika UR, Rao SR, Sahoo S, et al. Phenotypic and genotypic assays for detecting the prevalence of metallo- $\beta$-lactamases in clinical isolates of Acinetobacter baumannii from a South Indian tertiary care hospital. J Med Microbiol 2009;58(Pt 4):430-5.

[23] Ko KS, Suh JY, Kwon KT, et al. High rates of resistance to colistin and polymyxin $\mathrm{B}$ in subgroups of Acinetobacter baumannii isolates from Korea. J Antimicrob Chemother 2007;60(5):1163-7.

[24] Badave GK, Agarwal VA, Deogade NG. Is low virulence Acinetobacter baumannii acquiring virulence? Indian Journal of Medical Microbiology 2014;32(2):207-8.

[25] Goel V, Hogade SA, Karadesai SG. Prevalence of extended-spectrum beta-lactamases, AmpC beta-lactamase and metallo-beta-lactamase producing Pseudomonas aeruginosa and Acinetobacter baumannii in an intensive care unit in a tertiary care hospital. J Sci Soc 2013;40(1):28-31.
[26] Kaur A, Gupta V, Chhina D. Prevalence of metallo- $\beta$ lactamase-producing (MBL) Acinetobacter species in a tertiary care hospital. IRAN J Microbiol 2014;6(1): 22-5.

[27] Gupta N, Gandham N, Jadhav S, et al. Isolation and identification of Acinetobacter species with special reference to antibiotic resistance. J Nat Sci Biol Med 2015;6(1):159-62.

[28] Tan TY, Ng LS. Susceptibility of multi-resistant gramnegative bacilli in Singapore to tigecycline as tested by agar dilution. Ann Acad Med Singapore 2007;36(10):807-10.

[29] Manoharan A, Chatterjee S, Madhan S, et al. Evaluation of tigecycline activity in clinical isolates among Indian medical centers. Indian Journal of Pathology and Microbiology 2010;53(4):734-7. 